ORIGINAL ARTICLE

\title{
What constitutes a prescribing error in paediatrics?
}

\author{
M A Ghaleb, N Barber, B Dean Franklin, I C K Wong
}

Qual Saf Health Care 2005;14:352-357. doi: 10.1136/qshc.2005.013797

See end of article for authors' affiliations ......................

Correspondence to: Dr I C K Wong, Centre of Paediatric Pharmacy Research, School of Pharmacy, University of London, 29/39 Brunswick Square, London WCIN IAX, UK; ian.wong@ ulsop.ac.uk

Accepted for publication 1 August 2005
Objective: To develop a practitioner led definition of a prescribing error for use in prevalence/incidence studies in paediatric practice.

Design: A two stage Delphi technique was used to obtain the views of a panel of expert health professionals working in the hospital paediatric setting. The extent of their agreement on a definition of a prescribing error, and on 40 scenarios that might be classified as prescribing errors in paediatric practice, was obtained.

Results: Response rates were $84 \%(n=42)$ in the first Delphi round and $95 \%(n=40)$ in the second. Consensus was to accept the general definition of a prescribing error. In addition, there was consensus that 27 of the 40 scenarios should be included as prescribing errors, 10 should be excluded, and three may be considered prescribing errors depending on the individual clinical situation. Failure to communicate essential information, transcription errors and the use of drugs, formulations, or doses inappropriate for the individual patient were considered prescribing errors. Deviations from policies or guidelines, use of unlicensed and off-label drugs, and omission of non-essential information were not considered prescribing errors.

Conclusion: A general definition of a prescribing error has been developed that is applicable to the paediatric setting, together with more detailed guidance regarding the types of events that should be included. These findings are suitable for use in future research into the incidence and nature of prescribing errors in paediatrics.
$\mathrm{P}$ atient safety is a priority in healthcare systems across the world. Many patients appear to be harmed by errors every year, and around one third to one half of these errors might be avoidable. ${ }^{1-4}$ As a consequence, policy initiatives have been implemented in an attempt to reduce these adverse events. Medication errors are one of the most common causes of adverse events. They include prescribing, transcribing, dispensing, and administration errors. In the USA, medication errors kill 7000 patients a year ${ }^{4}$ and account for nearly one in 20 hospital admissions. ${ }^{5}$ In UK hospitals, the incidence of medication errors is similar to that reported in the USA-prescribing errors occur in $1.5 \%$ of prescriptions ${ }^{6}$ and administration errors in $3-8 \%$ of doses given. ${ }^{7}$

Most previous research has centred on medication errors and their prevention in adults. Limited evidence suggests that medication errors and corresponding harm could well be higher in children than in adults. ${ }^{89}$ In addition, most drug doses in paediatric medicine are calculated individually, based on the patient's age, weight, body surface area, and their clinical condition. This increases the likelihood of dosing errors. ${ }^{10}$

Limited work has been carried out in the UK to investigate paediatric medication errors; studies mostly rely on the analysis of incident reports which tend to be subject to substantial under-reporting. ${ }^{11-13}$

A major problem when interpreting quantitative studies of paediatric medication errors in general is variability in the definition of what constitutes an error. ${ }^{92-16}$ For example, some studies consider deviation from manufacturers' or institutional guidelines as an error while others have unclear definitions of the events considered as errors. ${ }^{91-13}$ Some studies do not give definitions at all. ${ }^{17}{ }^{18}$ One important aspect of medication errors is prescribing errors; limited work on pharmacists' interventions suggests that many errors occur and are subsequently remedied. ${ }^{19}{ }^{20}$ No large scale study has been performed on paediatric prescribing errors in the UK. A definition of paediatric prescribing errors needs to be established before such a study can be conducted.

The definition of an error is important as it can markedly affect the number of errors discovered. Some authors have set very high or inappropriate standards and hence most acts appear to be errors. ${ }^{21}$ Some definitions use other quality related terms-for example, the National Patient Safety Agency (NPSA) uses the National Co-ordinating Council for Medication Error and Prevention definition from the USA; however, this pivots on the idea of inappropriateness. In our view this is a different concept to error. In order for practitioners to believe studies of error (the first step leading to them changing their practice), the definition of error needs to be one that they believe in. Hence, the reason for our development of a practitioner based definition.

A practitioner based definition of a prescribing error has been developed in the UK for use in both research and practice. ${ }^{22}$ However, this definition was developed for use in the adult setting and issues specific to paediatric practice, such as the prescribing of drugs based on individual weight or age, were not considered. Our objective was therefore to develop a practitioner led definition of a prescribing error that could be applied to the paediatric setting. This definition could provide a foundation for future research into paediatric prescribing errors, particularly their epidemiology.

\section{METHODS}

A two stage Delphi technique ${ }^{2324}$ was used to obtain the views of a panel of expert participants about situations that should or should not be included as prescribing errors in paediatric practice. The Delphi technique was chosen over other consensus methods as it avoids the requirement for direct communication between groups of experts while still allowing a certain level of interaction between them. It is particularly useful when face to face contact is impractical. In addition, it places less pressure on group members to 


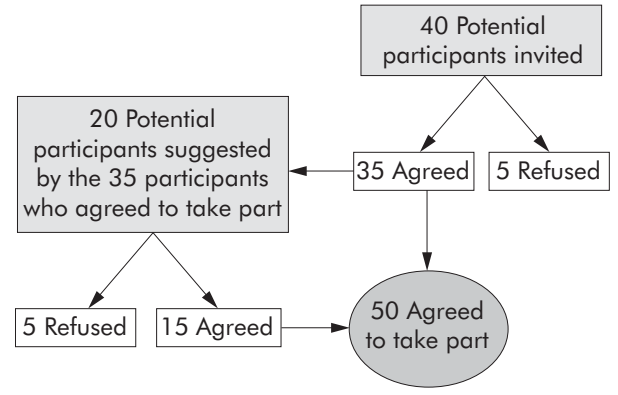

Figure 1 Summary of recruitment process showing number of participants who agreed to participate.

conform to one individual's view, and allows "bridge building" between participants where none was apparent before. ${ }^{24}$ The Delphi technique is being increasingly used in clinical guideline development. ${ }^{25}{ }^{26}$ In the Delphi technique, participants indicate the extent to which they agree with a series of statements in a postal questionnaire. Their scores are then summarised and included in a repeat version of the questionnaire so that each participant can reconsider his or her scores in view of the group's responses. Each participant's views are treated equally and each participant is anonymous to the remainder of the panel.

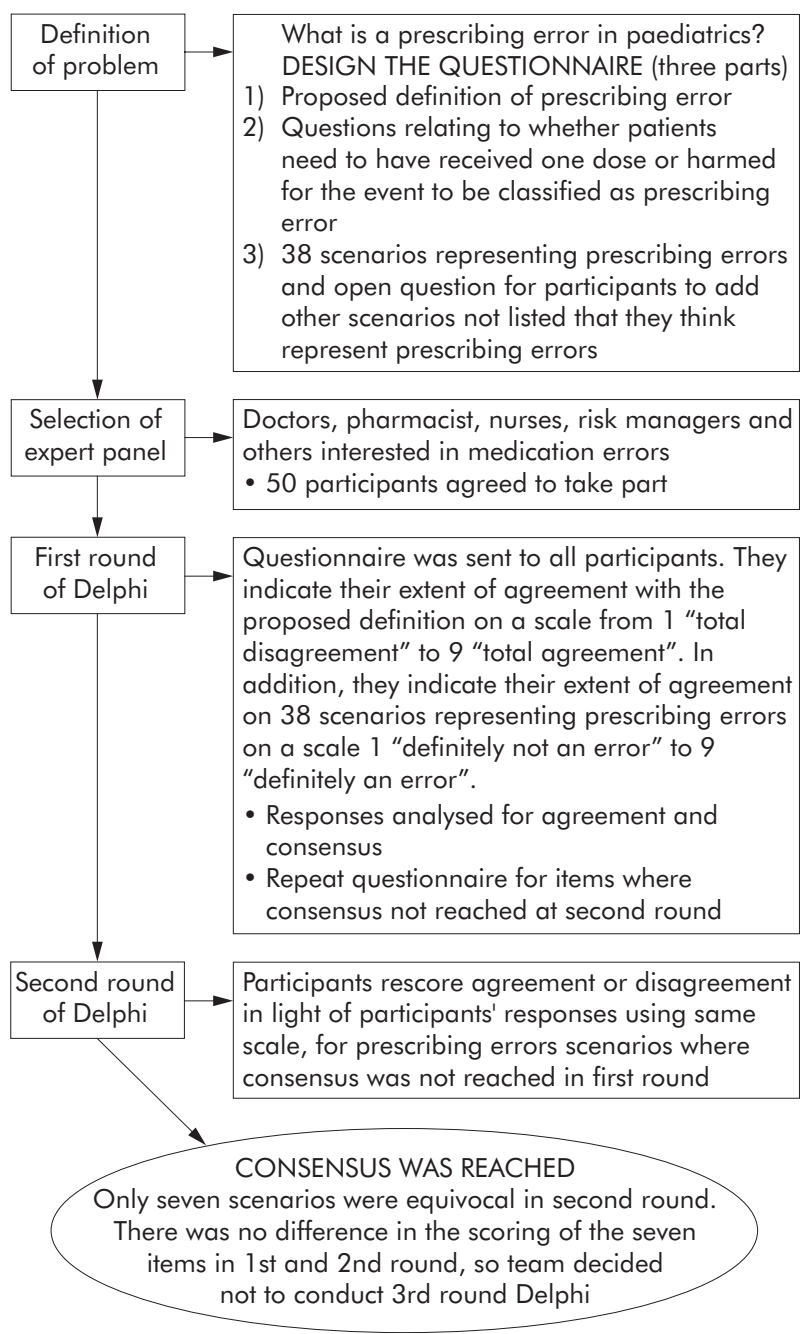

Figure 2 Delphi process used in the study.

\section{Expert panel selection}

It has been recommended that Delphi participants should have knowledge of the topic being investigated. ${ }^{27}$ Purposive sampling was used to select participants on the basis of their expertise in paediatrics and active involvement in patient care. The aim was to generate a cross section of professionals from teaching, specialist and general hospitals, and from a range of specialities (neonatal to adolescent). To develop practitioner led operational definitions, healthcare professionals selected included doctors, pharmacists, nurses, risk managers, and others with an interest in medication errors. The recruitment process is summarised in fig l. A total of 60 potential participants were invited to take part and, of these, 50 agreed to do so. No incentive (financial or otherwise) was offered to participants.

\section{The Delphi process}

A schematic diagram summarising the Delphi process is shown in fig 2.

\section{First round of Delphi process}

A literature search was used to identify previous definitions of a prescribing error used in paediatrics. Types of prescribing error that were included in some studies and excluded in others were identified. For example, some studies consider deviation from policies to be prescribing errors while others do not. In addition, the definition and scenarios of prescribing error developed by Dean et $a l^{22}$ were studied. This work was used to develop scenarios for use in the present study. The questionnaire developed was reviewed by the authors for content and layout and then piloted with two doctors, two pharmacists, and two nurses who were not included in the subsequent study panel. This resulted in the rewording of some scenarios to aid understanding.

A preliminary definition of prescribing error was proposed in the questionnaire; this definition had been developed using a Delphi process in a previous study ${ }^{22}$ and was as follows: "A clinically meaningful prescribing error occurs when, as a result of a prescribing decision or prescription writing process, there is an unintentional significant (1) reduction in the probability of treatment being timely and effective or (2) increase in the risk of harm when compared with generally accepted practice".

In addition, 38 scenarios were included that may represent prescribing errors, and the participants were asked to decide if these scenarios were considered an error or not. Participants were also asked to add any other scenarios which they thought represented prescribing errors in paediatric practice.

\section{Second round of Delphi process}

Only the definitions or scenarios where consensus was not reached in the first stage were included in this stage. The participants were asked to reconsider their scores having studied the whole panel's anonymised responses. They were provided with the following: (1) median and interquartile range of the whole panel's response for each definition or scenario; (2) comments made by individual (anonymous) participants together with the associated score; and (3) their own score relating to that scenario or definition.

The inclusion of the participants' comments and a summary of their responses increases the number of reasoned responses and decreases the number of rounds required in order to reach consensus. ${ }^{28}$

A third round of the Delphi process was not conducted as consensus was reached in all of the scenarios except seven. In these seven scenarios there was no difference in participants' scoring between rounds 1 and 2 , so it is unlikely that consensus would have been reached in a third round. 
Table 1 Demographic details of the 42 participants who took part in the Delphi process

\begin{tabular}{|c|c|c|c|}
\hline Profession & Grade & Speciality & Employer \\
\hline Doctor & Registrar & Paediatric surgery & Teaching hospital \\
\hline Doctor & Specialist registrar & Clinical pharmacology & Teaching hospital \\
\hline Doctor & Senior house officer & General paediatrics & Teaching general hospital \\
\hline Doctor & Senior house officer & Paediatrics & General hospital \\
\hline Doctor & Consultant & Paediatric infectious diseases & Teaching hospital \\
\hline Doctor & Consultant & Paediatrics & General hospital \\
\hline Doctor & Consultant & Paediatrics & General hospital \\
\hline Doctor & Consultant & Paediatric oncology & Specialist hospital \\
\hline Doctor & Consultant & Paediatric anaesthesia & Specialist hospital \\
\hline Doctor & Consultant & General paediatrics & Other \\
\hline Doctor & Consultant & Gastroenterology & Other \\
\hline Doctor & Senior academic & Child health & Specialist teaching hospital \\
\hline Doctor & Senior academic & Child health & Other \\
\hline Doctor & Director & Risk management & Specialist teaching hospital \\
\hline Pharmacist & Senior & Clinical pharmacy & General hospital \\
\hline Pharmacist & Senior & Clinical pharmacy & General hospital \\
\hline Pharmacist & Senior & Paediatric surgery & General hospital \\
\hline Pharmacist & Senior & Clinical pharmacy & General hospital \\
\hline Pharmacist & Senior & General paediatrics & General teaching hospital \\
\hline Pharmacist & Senior & Paediatric cardiology & General hospital \\
\hline Pharmacist & Senior & Paediatric clinical trials & Specialist general hospital \\
\hline Pharmacist & Senior & Paediatric surgery & Teaching hospital \\
\hline Pharmacist & Senior & Critical care & Teaching hospital \\
\hline Pharmacist & Senior & Paediatric general medicine & Specialist teaching hospital \\
\hline Pharmacist & Senior academic & Clinical pharmacy & Specialist teaching hospital \\
\hline Pharmacist & Senior manager & Clinical effectiveness & Specialist teaching hospital \\
\hline Pharmacist & Chief & General paediatrics & Specialist teaching hospital \\
\hline Pharmacist & Chief & Clinical pharmacy & Specialist general hospital \\
\hline Pharmacist* & Chief & Paediatric respiratory & Specialist hospital \\
\hline Pharmacist & Director & Clinical pharmacy & General hospital \\
\hline Pharmacist & Director & Clinical pharmacy & General hospital \\
\hline Pharmacist & Principal & General paediatrics & Teaching general hospital \\
\hline Nurse & Charge nurse & Paediatric surgery & General hospital \\
\hline Nurse & Senior staff nurse & General paediatrics & Specialist teaching hospital \\
\hline Nurse & Senior manager & Specialist in paediatric critical care & Teaching hospital \\
\hline Nurse & Senior manager & General paediatrics & General hospital \\
\hline Nurse & Senior manager & Professional body & Other \\
\hline Risk manager & Senior manager & Pharmacy & Specialist teaching hospital \\
\hline Risk manager & Senior manager & Risk management & General hospital \\
\hline Risk manager & Senior academic & Risk management & Specialist teaching hospital \\
\hline Risk manager* & Clinical governance manager & Risk management & General teaching hospital \\
\hline Other & Senior academic & Pharmacology & Other \\
\hline
\end{tabular}

\section{Analysis of data}

The following definitions were specified before analysis: ${ }^{24}$ "Consensus" was considered to exist if the interquartile range of the participants' responses fell within any three point range; "disagreement" existed if the interquartile range spanned both the 1-3 range and the 7-9 range. If neither consensus nor disagreement existed, "partial agreement" was considered to have occurred.

Where consensus existed, it was considered that the scenario would be included as a prescribing error if the median score fell within the 7-9 range, that it should be excluded if it fell within the 1-3 range, and that it was equivocal if it fell within the $4-6$ range. ${ }^{24}$ If the consensus was that the scenario was equivocal, or if consensus was not obtained at the end of the second stage, the participants' additional comments, together with their scores, were used to decide whether or not to classify each scenario as a prescribing error.

Ethical approval was obtained from Thames Valley multicentre research ethics committee.

\section{RESULTS}

\section{Response rate}

Seventeen doctors, 20 pharmacists, eight nurses, four risk managers, and an expert in medication errors agreed to take part. Forty two (84\%) of the 50 participants responded to the first round of the Delphi process. Responses for the second round were received from 40 (95\%) of the 42 participants who responded to the first round. The demographic details of the participants are shown in table 1 .

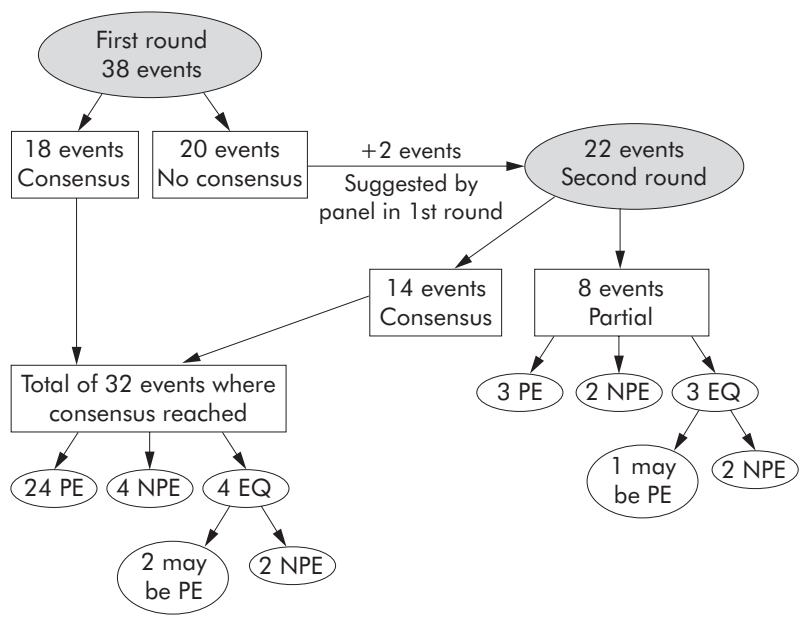

Figure 3 Consensus process, summarising the number of events in the first and second Delphi rounds. PE, prescribing error; NPE, not prescribing error; $E Q$, equivocal. 
Table 2 Situations that should be included as prescribing errors

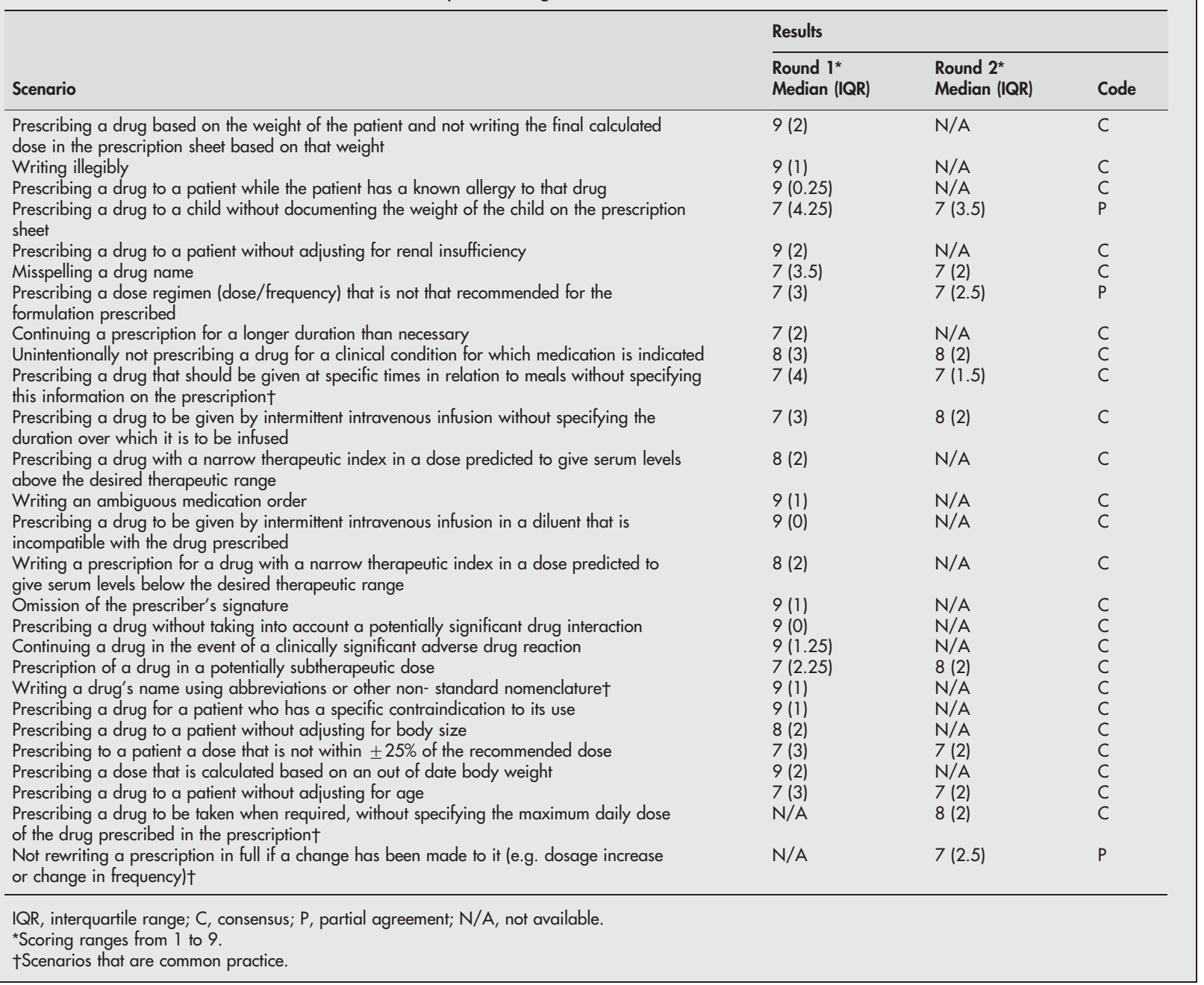

\section{Definition of a prescribing error}

The participants' median score was 7.0 and the interquartile range 6.0-8.0, indicating that consensus was to accept the researchers' proposed definition. Twenty six (62\%) of the 42 respondents made additional comments relating to problems with the definition. Most of these comments were related to the words "significant" and "harm", the phrases "clinically meaningful medication error" and "generally accepted practice".

Of the 26 comments, 23 were critical of some aspects of the definition. The most common comment $(n=9)$ was that "significance" was a subjective term and hard to define. Similar comments were made about "harm" $(n=4)$. This is understandable as significance, harm and, indeed, error, are social constructs about value and hence should be subjective. Dean and Barber have suggested methods elsewhere, using generalisability theory, to deal with these variations. ${ }^{29}$ Of the remaining comments, three were related to the phrase "clinical meaningful", three to the term "timely", two to the phrase "generally accepted practice"; it was considered that these terms are liable to various interpretations. Two of the remaining comments stated that the definition is not easily remembered.

It was decided to keep the initial proposed definition of a prescribing error as consensus was reached and the majority of the participants were satisfied with it. The definition was as follows: "A clinically meaningful prescribing error occurs when, as a result of a prescribing decision or prescription writing process, there is an unintentional significant (1) reduction in the probability of treatment being timely and effective or (2) increase in the risk of harm when compared with generally accepted practice".

The terms "significant", "clinically meaningful", and "generally accepted practice" were included to differentiate between clinically meaningful prescribing errors and other situations where some optimisation of treatment was possible but where a prescribing error could not be said to have occurred.

\section{Near misses and harm}

When asked, all participants agreed that it was not necessary for the patient to have received one or more doses of the drug or to have been harmed for the error to be included.

\section{Type of events to be included as prescribing errors}

Figure 3 summarises the consensus process. Following the first Delphi round, consensus was reached for 18 (47\%) of 38 events. Participants were asked in the first round to suggest any additional scenarios or events that might represent prescribing errors in paediatrics. Two scenarios were added: (1) prescribing a drug to be administered when required without indicating the maximum daily dose, and (2) not rewriting the prescription in full if a change has been made to it. Only the $20(53 \%)$ events for which no consensus was achieved in the first round were included in the second stage, in addition to the two scenarios suggested by participants (described above), making a total of 22 events forwarded to 
Table 3 Situations that should be excluded as prescribing errors

\begin{tabular}{|c|c|c|c|}
\hline \multirow[b]{2}{*}{ Scenario } & \multicolumn{3}{|l|}{ Results } \\
\hline & $\begin{array}{l}\text { Round } 1^{*} \\
\text { Median (IQR) }\end{array}$ & $\begin{array}{l}\text { Round } 2^{*} \\
\text { Median (IQR) }\end{array}$ & Code \\
\hline $\begin{array}{l}\text { Prescribing a drug for a patient and not including the dosage equation } \\
\text { (e.g. } \mathrm{mg} / \mathrm{kg} \text { ) on the prescription sheet }\end{array}$ & $1(1.25)$ & $\mathrm{N} / \mathrm{A}$ & C, EX \\
\hline $\begin{array}{l}\text { Prescribing for a child a drug that is appropriate for the condition but has no } \\
\text { product licence for use in children }\end{array}$ & $1(1)$ & $\mathrm{N} / \mathrm{A}$ & $C, E X$ \\
\hline Prescribing a drug that is not in the hospital formulary & $2(3)$ & $2(1.75)$ & C, EX \\
\hline Prescribing for an indication that is not in the drug's product licence & $2(2.25)$ & $2(1)$ & C, EX \\
\hline Prescribing by the brand name (as opposed to the generic name) & $3.5(4.25)$ & $3(4)$ & $P, E X$ \\
\hline $\begin{array}{l}\text { Prescribing a dose that cannot readily be administered using the dosage } \\
\text { forms available }\end{array}$ & $6(4)$ & $3(2.75)$ & $P, E X$ \\
\hline $\begin{array}{l}\text { Prescribing a drug in a dose above the maximum dose recommended in the } \\
\text { British National Formulary (BNF), Summary of product characteristics (SPC), } \\
\text { or reference sources (e.g. Medicines for Children published by the Royal } \\
\text { Pharmaceutical Society of Great Britain) }\end{array}$ & $6(3)$ & $6(2)$ & $C, E Q$ \\
\hline Prescribing contrary to national treatment guidelines & $5(4)$ & $5.5(3)$ & $P, E Q$ \\
\hline $\begin{array}{l}\text { Prescribing to a patient a drug that is not according to standard paediatric } \\
\text { references }\end{array}$ & $6(3)$ & $6(2)$ & $C, E Q$ \\
\hline Prescribing contrary to hospital treatment guidelines & $5(4)$ & $5(2.5)$ & $P, E Q$ \\
\hline
\end{tabular}

the second round. Following the second round, consensus was achieved for a further 14 of the 22 events. Of the remaining eight, partial agreement existed. The consensus and decision process is summarised in fig 3. Based on the participants' comments, it was decided that, of the seven events where it was equivocal in the first and the second rounds, four were excluded as prescribing errors and three may be considered prescribing errors depending on the individual clinical situation.

Table 2 shows the situations that should be included as prescribing errors, table 3 shows the situations that should be excluded, and table 4 shows the situations that may be considered prescribing errors depending on the individual clinical situation.

In general, events classed as prescribing errors were concerned with the selection of drugs, doses, and impractical doses (not easily prepared or administered). The scenarios not considered to be prescribing errors generally represented non-adherence to rules such as the use of off-label or unlicensed products in paediatrics, and deviations from guidelines and policies.

\section{DISCUSSION}

Following the use of the Delphi technique, a general definition of a prescribing error was agreed for use in the paediatric setting. In addition, guidance concerning the types of events that should be included as prescribing errors has been developed.

Participants in this study expressed their agreement with the proposed prescribing error definition (as previously developed by Dean et $a l^{22}$ for use in general settings) for use in the paediatric setting. This, in turn, confirms the generalisability of the previous definition.

The 40 scenarios assessed by the participants were classified into prescribing errors, not prescribing errors, and those that were equivocal (these would or would not be considered prescribing errors depending on the clinical situation). Prescribing without taking into account the patient's clinical condition or weight, not taking into account important pharmaceutical issues, and failure to include or communicate essential information were all considered prescribing errors. Some of these scenarios are common practice (indicated by $\uparrow$ in table 2 ); however, the participants considered them prescribing errors. Generally, non-adherence to organisational rules-for example, failure to adhere to hospital, national and paediatric guidelines, not including dosage equations in the prescription, use of unlicensed and off-label drugs, and prescribing by brand name- was not considered to be a prescribing error. Deviations from guidelines were not considered prescribing errors as long as the prescriber provided a valid reason for the deviation. This raises the question about the validity of paediatric prescribing error studies that define errors based on deviation from guidelines. ${ }^{8} 1730$

Our findings are similar to those of Dean $e^{a l^{22}}$ who studied hospital prescribing errors in a general setting.

We identified five potential limitations of this study. (1) The response rates in both rounds were less than $100 \%$. Bias may have been introduced through the missing responses of participants who may have specific expertise. However, examination of the data in this study suggests that nonrespondents to the second round have typical first round

Table 4 Situations that may be considered prescribing errors depending on the individual clinical situation

\begin{tabular}{|c|c|c|c|}
\hline \multirow[b]{2}{*}{ Scenario } & \multicolumn{3}{|l|}{ Results } \\
\hline & $\begin{array}{l}\text { Round } 1^{*} \\
\text { Median (IQR) }\end{array}$ & $\begin{array}{l}\text { Round } 2^{*} \\
\text { Median (IQR) }\end{array}$ & Code \\
\hline $\begin{array}{l}\text { Prescribing a drug for which there is no documented indication for that patient } \\
\text { Prescribing a drug for which there is no evidence of efficacy and safety for use } \\
\text { in the patient population }\end{array}$ & $\begin{array}{l}5(3.5) \\
5(4)\end{array}$ & $\begin{array}{l}5(2) \\
5(3)\end{array}$ & $\begin{array}{l}\text { C, EQ } \\
P, E Q\end{array}$ \\
\hline $\begin{array}{l}\text { Prescribing a formulation for which there is no evidence of efficacy and safety for } \\
\text { use in the patient population }\end{array}$ & $5(4)$ & $5(2)$ & $C, E Q$ \\
\hline
\end{tabular}

use in the patient population

$I Q R$, interquartile range; $C$, consensus; $P$, partial agreement; $E Q$, equivocal.

*Scoring ranges from 1 to 9 . 
scores. (2) We cannot authoritatively say that our definition could be applied to community practice. (3) Consensus existed if $50 \%$ of the participants' scores fell within any 3 point range. Others consider this definition of consensus as a relaxed one (that is, consensus was reached in a larger number of cases than if a stricter definition of consensus was used). ${ }^{31}$ In the literature there is no standard method of defining consensus, and it has been recommended that an appropriate definition be used to fit the objectives of the study. ${ }^{26}$ (4) It was not possible to use a random sample of healthcare professionals. While purposive sampling could be seen as biased, it ensured a reasonable sample size representing a wide range of professions and experiences, which is important in consensus building. On the other hand, 60 participants were invited to take part of which 50 (83.3\%) agreed. This high response rate adds to the validity. (5) We only conducted two rounds; however, we already had a high degree of consensus and one of the potential problems of the use of Delphi technique is panel fatigue.

Currently, the definition developed is being used to establish the incidence and nature of paediatric prescribing errors across different UK hospitals. It has proved to be helpful in deciding what should be included as prescribing errors and what should not. Our definition of a prescribing error in the general setting has been used by the Department of Health. ${ }^{32}$ It has the advantage of referencing error to usual practice, and of not artificially inflating the error rate by including trivial incidents or breaches of inappropriate guidance. As there is no existing standard definition of a prescribing error in paediatrics, it is hoped that other researchers will adopt this definition to study prescribing errors, to allow comparison between studies. Worldwide there is no standard definition of prescribing error, so the definition and scenarios could be used internationally as a guidance of what constitutes a prescribing error, and could be used in studying prescribing errors.

In conclusion, consensus was reached regarding the definition of a prescribing error and its applicability in the paediatric setting, together with guidance on the scenarios that should be included and excluded as prescribing errors.

\section{ACKNOWLEDGEMENTS}

The authors thank all the participants in the expert panel.

\footnotetext{
Authors' affiliations

M A Ghaleb, I C K Wong, Centre for Paediatric Pharmacy Research, School of Pharmacy, University of London and Institute of Child Health, University College London, UK

M A Ghaleb, N Barber, B Dean Franklin, I C K Wong, Department of Practice and Policy, School of Pharmacy, University of London, UK B Dean Franklin, Academic Pharmacy Unit, Hammersmith Hospitals NHS Trust, UK

MG is partly funded by a UK Overseas Research Scholarship. IW is funded by a UK Department of Health, National Public Health Career Scientist Award. NB, BDF and IW have received funding from the UK Medical Research Council and UK Department of Health in the research of medication errors and the use of technology in their reduction.

No competing interests.
}

\section{REFERENCES}

1 Anon. Second national report on patient safety: improving medication safety. Australia: Australian Council for Safety and Quality in Health Care, 2004.

2 Department of Health. An organization with a memory. London: The Stationery Office, 2000.

3 Department of Health. Building a safer NHS for patients. London: The Stationery Office, 2001.

4 Kohn LT, Corrigan JM, Donaldson MS. To err is human: building a safer health system. Washington, DC: Institute of Medicine National Academy Press, 1999.

5 Hepler CD, Segal R. Preventing medication errors and improving drug therapy outcomes. Florida: CRC Press, 2003.

6 Dean B, Schachter M, Vincent C, et al. Prescribing errors in hospital inpatients: their incidence and clinical significance. Qual Saf Health Care 2002;11:340-4.

7 Dean B. Errors in medication administration. Intensive Care Med 1999;25:341-2.

8 Blum KV, Abel SR, Urbanski CJ, et al. Medication error prevention by pharmacists. Am J Hosp Pharm 1988;45:1902-3.

9 Kaushal R, Bates DW, Landrigan C, et al. Medication errors and adverse drug events in pediatric inpatients. JAMA 2001;285:2114-20.

10 Wong IC, Ghaleb MA, Franklin BD, et al. Incidence and nature of dosing errors in paediatric medications: a systematic review. Drug Saf 2004; 27:661-70.

11 Paton J, Wallace J. Medication errors. Lancet 1997;349:959-60.

12 Ross LM, Wallace J, Paton JY. Medication errors in a paediatric teaching hospital in the UK: five years operational experience. Arch Dis Child 2000;83:492-7.

13 Wilson DG, McArtney RG, Newcombe RG, et al. Medication errors in paediatric practice: insights from a continuous quality improvement approach. Eur J Pediatr 1998:9:769-74.

14 Kozer E, Scolnik D, Macpherson A, et al. Variables associated with medication errors in pediatric emergency medicine. Pediatrics 2002; 1 10:737-42.

15 Marino BL, Reinhardt K, Eichelberger WJ, et al. Prevalence of errors in a pediatric hospital medication system: implications for error proofing. Outcomes Manag Nurs Pract 2000;4:129-35.

16 Raju TN, Kecskes S, Thornton JP, et al. Medication errors in neonatal and paediatric intensive-care units. Lancet 1989;2:374-6.

17 Selbst SM, Fein JA, Osterhoudt K, et al. Medication errors in a pediatric emergency department. Pediatr Emerg Care 1999;15:1-4.

18 Vincer MJ, Murray JM, Yuill A, et al. Drug errors and incidents in a neonatal intensive care unit. A quality assurance activity. Am J Dis Child 1989;143:737-40.

19 Guy J, Persaud J, Davies E, et al. Drug errors: what role do nurses and pharmacists have in minimizing the risk? J Child Health Care 2003;7:277-90.

20 Barber ND, Batty R, Ridout DA. Predicting the rate of physician accepted interventions by hospital pharmacists in the United Kingdom. Am J Health Syst Pharm 1997;54:397-405.

21 Hartley G, Dhillon S. An observational study of the prescribing and administration of intravenous drugs in a general hospital. Int J Pharm Pract 1998;6:38-45.

22 Dean B, Barber N, Schachter M. What is a prescribing error? Qual Health Care 2000;9:232-7.

23 Bowles N. The Delphi technique. Nurs Stand 1999;13:32-6.

24 Jones J, Hunter D. Consensus methods for medical and health services research. BMJ 1995;311:376-80.

25 Beretta R. A critical review of the Delphi technique. Nurse Researcher 1996;3:79-89.

26 Murphy MK, Black NA, Lamping DL, et al. Consensus development methods, and their use in clinical guideline development. Health Technol Assess 1998;2:2p

27 Hasson F, Keeney S, McKenna H. Research guidelines for the Delphi survey technique. J Adv Nurs 2000;32:1008-15.

28 Duffield C. The Delphi technique: a comparison of results obtained using two expert panels. Int J Nurs Stud 1993;30:227-37

29 Dean BS, Barber ND. A validated, reliable method for scoring the severity of medication errors. Am J Health Syst Pharm 1999;56:57-62.

30 Folli HL, Poole RL, Benitz WE, et al. Medication error prevention by clinical pharmacists in two children's hospitals. Pediatrics 1987;79:718-22.

31 Scott EA, Black N. When does consensus exist in expert panels? J Public Health Med 1991;13:35-9.

32 Department of Health. Building, a safer NHS for patients: improving medication safety. London: The Stationery Office, 2004 